\title{
Rupture of the Right Atrium Following a Closed-Chest Cardiac Massage
}

\author{
Chan Yong Park \\ Department of Trauma Surgery, Pusan National University Hospital, Busan, Korea
}

Cardiac rupture is a rare complication of CPR but is usually fatal when it occurs. Here we report a 59-year-old woman who developed cardiac rupture which was caused by a fracture of the sternum and ribs associated with closed-chest cardiac massage.

(Trauma Image Proced 2017(2):64-65)

Key Words: Cardiac rupture; Fracture of sternum; Closed-chest cardiac massage

\section{CASE}

A 59-year-old female presented to the emergency department due to stab injury on her left thigh. Cardiopulmonary resuscitation had been performed on the way to hospital by an Emergency Service Team due to cardiac arrest. Upon arrival at the emergency department, her initial Hemoglobin was $4.5 \mathrm{~g} / \mathrm{dl}$, ECG showed asystole, and the sternum was fractured due to the closed-chest cardiac massage. Postmortem examination revealed a fracture of the sternum and multiple ribs, approximately $300 \mathrm{ml}$ of fluid blood in the pericardial sac (Fig. 1.), and a $2 \times 2$-cm-sized free perforation in the right atrium (Fig. 2.). There was no tear in the pericardium.

\section{DISCUSSION}

Since its introduction in the 1960 's, there have been many complications resulting from closed-chest cardiac massage including regurgitation, aspiration, and rib and sternal fractures (1). Cardiac rupture is a rare complication of CPR however it is usually fatal when it occurs. Early diagnosis and treatment is a very important factor for positive prognosis (2). While direct cardiac injuries resulting from penetration are usually readily recognized and appropriately handled, the etiologic relation of non-penetrating and indirect cardiac injuries are often overlooked, either at the time of injury or when complications are latent (3).

Cardiac rupture is a rare complication of CPR (4-6). Blunt cardiac trauma, with an estimated incidence of $0.1 \%$, can cause a cardiac rupture, cardiac contusion or commotio cordis (3). Twenty-one percent of the patients had at least one complication because of CPR. Postmortem examination revealed cardiac rupture or pericardial hematoma related to CPR in $8 \%$ of unsuccessfully resuscitated subjects $(7,8)$.

Received: October 31, 2017 Revised: November 8, 2017 Accepted: November 8, 2017

Correspondence to: Chan Yong Park, Department of Trauma Surgery, Pusan National University Hospital, 179, Gudeok-Ro, Seo-Gu, Busan, 49241, Korea

Tel: 82-51-240-7369, Fax: 82-51-240-7719, E-mail: wkafyddl@hanmail.net

Copyright (c) 2017 Korean Association for Research, Procedures and Education on Trauma. All rights reserved.

(c) This is an open-access article distributed under the terms of the Creative Commons Attribution Non-Commercial License (http://creativecommons.org/ licenses/by-nc/4.0) which permits unrestricted noncommercial use, distribution, and reproduction in any medium, provided the original work is properly cited 


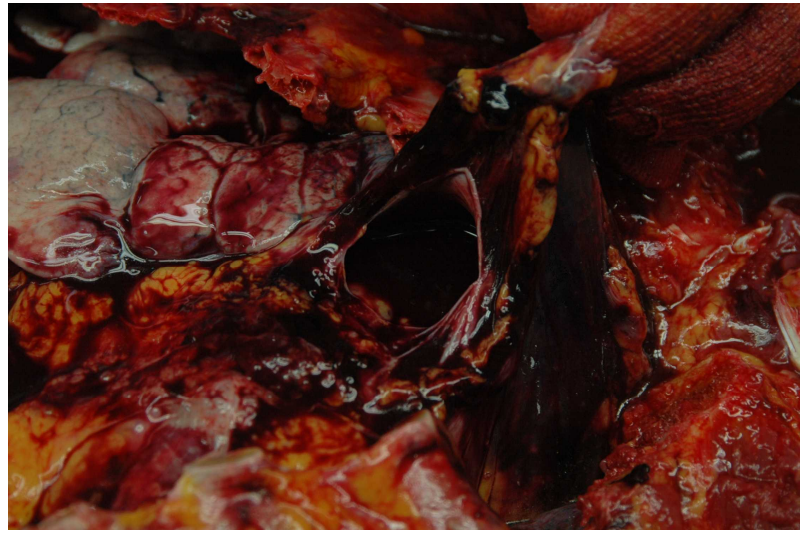

Fig. 1. After opening the pericardial sac, a large amount of fluid blood was observed (The sternum was removed, and the pericardium was opened).

Several factors are involved in the development of complications related to CPR such as age, build of the patient, duration of resuscitation, and skill of the emergency medical technicians. The time spent on resuscitation also contributes to the development of complications (5). Cardiac rupture is caused by direct penetration of the fractured sternum or ends of fractured ribs $(5,6,9,10)$. In our case,

Permanyer et al. (10) reported a right atrium traumatic rupture presenting as chronic tamponade after CPR. Postmortum findings revealed a $2 \times 3$-cm-sized rupture of the base of the right atrium.

An autopsy revealed a fracture of the sternum and multiple ribs, about $300 \mathrm{ml}$ of blood in pericardial space, and about a $2 \times 2$-cm-sized free perforation in the right atrium. A large amount of blood in pericardial sac can cause pericardial tamponade.

In this patient, the cause of rupture of the right atrium is likely related to closed-chest cardiac massage, and the cause of death was pericardial tamponade. Therefore, vigorous CPR performed in cardiac arrest can result in a lethal cardiac rupture and tamponade

\section{Conflict of Interest Statement}

None of authors has a conflict of interest.

\section{REFERENCES}

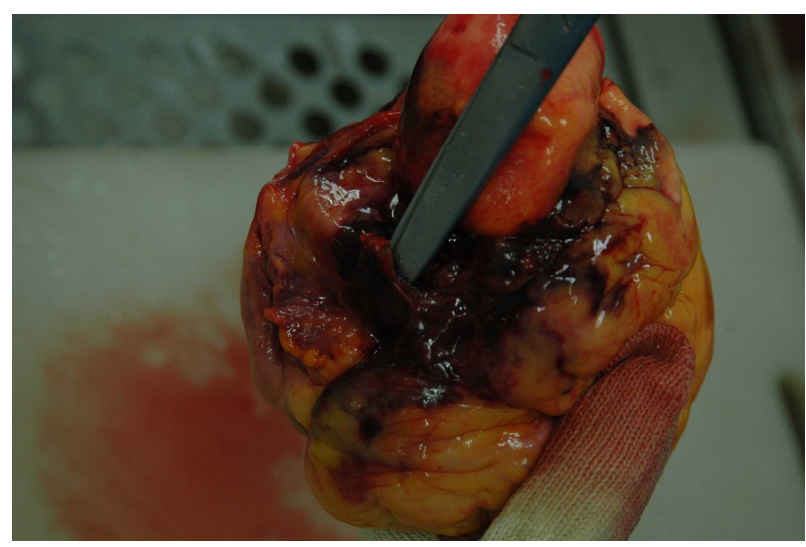

Fig. 2. A $2 \times 2-\mathrm{cm}$-sized free perforation was observed in the right atrium.

1. Krischer JP, Fine EG, Davis JH, Nagel EL. Complications of cardiac Resuscitation. Chest 1987;92(2):287-91.

2. Ilkjaer LB, Mikkelsen SS. Rupture of the right atrium after blunt trauma. Ugeskr Laeger 2001;163(43):5986-7.

3. Parmley LF, Mattingly TW, Manion WC, Jahnke EJ Jr. Nonpenetrating traumatic injury of the aorta. Circulation 1958;17(6):1086-101.

4. Mangold S, Miller S, Aebert $H$. Rupture of the right ventricle after closed-chest cardiac massage. Circulation 2010;122(16):1657.

5. Machii $M$, Inaba $H$, Nakae $H$, Suzuki I, Tanaka $H$. Cardiac rupture by penetration of fractured sternum: a rare complication of cardiopulmonary resuscitation. Resuscitation 2000;43(2):151-3.

6. Klintschar M, Darok M, Radner H. Massive injury to the heart after attempted active compression-decompression cardiopulmonary resuscitation. Int J Legal Med 1998; 111(2):93-6.

7. Bedell SE, Fulton EJ. Unexpected findings and complications at autopsy after cardiopulmonary resuscitation (CPR). Arch Intern Med 1986;146(9):1725-8.

8. Nagel EL, Fine EG, Krischer JP, Davis JH. Complications of CPR. Crit Care Med 1981;9(5):424.

9. Noffsinger AE, Blisard KS, Balko MG. Cardiac laceration and pericardial tamponade due to cardiopulmonary resuscitation after myocardial infarction. J Forensic Sci 1991; 36(6):1760-4.

10. Permanyer E, Ginel A, Munoz-Guijosa C, Padro JM. Right atrium traumatic rupture presenting as chronic tamponade. Interact Cardiovasc Thorac Surg 2009;9(4): 748-9. 